\title{
MODIFICAÇÃO DE ZEÓlITAS PARA USO EM CATÁlISE
}

\section{Fernando J. Luna*}

Laboratório de Ciências Químicas - CCT, Universidade Estadual do Norte Fluminense, Av. Alberto Lamego, 2000, 28015-620

Campos dos Goytacazes - RJ

Ulf Schuchardt

Instituto de Química, Universidade Estadual de Campinas, CP 6154, 13083-970 Campinas - SP

Recebido em 27/10/00; aceito em 7/3/01

\begin{abstract}
MODIFYING ZEOLITES FOR USE IN CATALYSIS: The use of zeolites and other molecular sieves as catalysts is discussed at an introductory level. The text includes a brief historic background on the use of zeolites in catalysis, and a discussion of some chemical and physical properties of silicalite, aluminosilicate, and aluminophosphate molecular sieves. The strategies currently used to chemically modify zeolites and related materials to produce catalysts with increased activity and selectivity are discussed, including the use of redox molecular sieves for hydrocarbon oxidation and the leaching of the active metals from the support.
\end{abstract}

Keywords: molecular sieves; zeolites; catalysts; heterogeneous catalysis.

\section{INTRODUÇÃO}

Doze séculos antes de Berzelius estabelecer o conceito e os princípios da catálise, alquimistas árabes já utilizavam catalisadores para produzir éter ${ }^{1}$. Em 1756, o barão sueco Axel Cronstedt não chegou a concluir que suas pedras "ferviam" " por causa da água armazenada nos microporos ${ }^{2}$. Duzentos anos de trabalho científico acumulado foram necessários para que McBain criasse o conceito de peneira molecular em $1932^{3}$. O termo se aplica a sólidos porosos capazes de adsorver seletivamente moléculas cujo tamanho permite sua entrada dentro dos canais, como ilustrado na Figura 1.

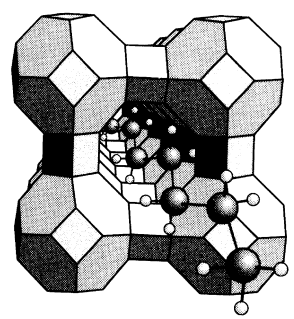

$a$

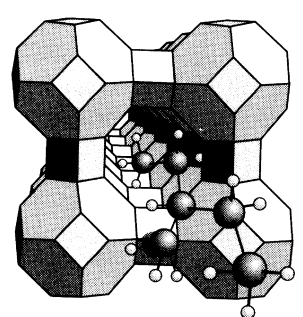

$b$
Figura 1. Em (a), moléculas lineares são adsorvidas pela zeólita A, mas o volume excessivo da molécula ramificada impede a penetração nos poros em $(b)^{4}$.

No entanto, somente há três décadas zeólitas, como a estilbita de Cronstedt, começaram a ser empregadas como catalisadores para as mais variadas reações químicas ${ }^{5}$. Um breve histórico dos principais desenvolvimentos da Ciência relacionados à catálise com peneiras moleculares é mostrado na Tabela 1 .

A partir da aplicação pioneira em 1962 em processos de craqueamento de petróleo, as zeólitas assumiram hoje a posição de catalisadores mais importantes na indústria química ${ }^{6}$.

e-mails: fernando@uenf.br, ulf@iqm.unicamp.br

Cronstedt descobriu uma nova classe de minerais que denominou zeólitas, em grego "pedra que ferve", porque quando aquecidas com um maçarico, observa-se a eliminação de vapor d’água.
As zeólitas são consideradas os materiais mais promissores na busca da pedra filosofal do químico contemporâneo: o catalisador ideal. O mecanismo desse catalisador onírico funcionaria como uma pinça molecular, imobilizando cada molécula de substrato na posição apropriada para romper somente a ligação química necessária a fim de formar o produto esperado com altíssima atividade e seletividade absoluta ${ }^{7}$.

\section{ZEÓLITAS E MATERIAIS ANÁLOGOS}

Segundo a definição clássica, o termo zeólitas abrange somente aluminossilicatos cristalinos hidratados de estrutura aberta, constituída por tetraedros de $\mathrm{SiO}_{4}$ e $\mathrm{AlO}_{4}$ ligados entre si pelos átomos de oxigênio ${ }^{5}$. A rigor, somente esses materiais podem ser chamados de zeólitas; no entanto, é razoável advogar que o uso desse termo seja estendido para designar estruturas análogas contendo também tetraedros de outros elementos $\left(\mathrm{PO}_{4}, \mathrm{GaO}_{4}\right.$, etc.). Zeólitas têm sido utilizadas principalmente como adsorventes para purificação de gases e como trocadores iônicos em detergentes, mas se mostram extremamente úteis como catalisadores no refino de petróleo ${ }^{9}$, na petroquímica ${ }^{6}$, e na síntese de produtos orgânicos cujas moléculas possuem diâmetro cinético inferior a $10 \AA^{10,11}$.

A síntese de zeólitas com poros de diâmetros maiores para utilização no processamento de moléculas mais volumosas, típicas de produtos farmacêuticos e na química fina, tem sido um dos principais desafios enfrentados por pesquisadores na última década ${ }^{2}$. A criação dos aluminofosfatos, uma nova classe de zeólitas, em 1982, abriu caminho para a síntese de estruturas de poros maiores do que até então conhecidas ${ }^{13}$, como o VPI- $5^{14}$ e a cloverita ${ }^{15}$, e de composições químicas variadas, incluindo galofosfatos ${ }^{14} \mathrm{e}$ cobaltofosfatos ${ }^{16}$.

A eficiência das zeólitas em catálise se deve a algumas características peculiares desses materiais. Zeólitas possuem: (i) altas área superficial e capacidade de adsorção ${ }^{8}$; (ii) propriedades de adsorção que variam num amplo espectro desde altamente hidrofóbicas a altamente hidrofílicas ${ }^{17}$; (iii) uma estrutura que permite a criação de sítios ativos, tais como sítios ácidos, cuja força e concentração podem ser controladas de acordo com a aplicação desejada ${ }^{18}$; (iv) tamanho de canais e cavidades compatíveis com a maioria das moléculas das matérias-primas usadas na indústria ${ }^{19}$; e (v) uma complexa rede de canais que lhes confere diferentes tipos de seletividade de forma $\mathrm{a}^{20,21}$, i.e., seletividade de reagente, de produto e de estado de transição, como esquematizados na Figura $2^{22}$. 
Tabela 1. Catálise e peneiras moleculares: marcos históricos ${ }^{1,3,4,5,8}$.

\begin{tabular}{ll} 
Séc. VIII & Jabir Ibn Haiyan (Geber) descreve a desidratação de álcool para produzir éter utilizando ácido sulfúrico como \\
& catalisador \\
1756 & Cronstedt descobre as zeólitas (em grego, zeo=que ferve, lithos=pedra) \\
1836 & Berzelius cria o termo "catálise" (em grego, katalusis significa dissolução) \\
1845 & Síntese hidrotérmica de quartzo a partir de gel de sílica por Schafhautle \\
1862 & St. Claire Deville faz a $1^{\text {a }}$ síntese (hidrotérmica) de zeólita: a levinita \\
1895 & Ostwald estabelece a natureza cinética da catálise \\
1911 & Sabatier sugere existirem intermediários na superfície de catalisadores \\
1925 & Weigel e Steinhoff observam o efeito de peneira molecular na chabazita \\
1930 & Primeira determinação de estrutura de zeólita é feita por Taylor e Pauling \\
1932 & McBain introduz o conceito de peneira molecular \\
1936 & Craqueio catalítico: Processo Houdry com SiO ${ }_{2}$-Al $\mathrm{O}_{3}$ \\
1938 & Brunauer, Emmet e Teller descrevem método para medir área específica \\
1945 & Richard Barrer classifica zeólitas baseado em propriedades de peneira molecular \\
1948 & Milton sintetiza zeólitas de estrutura desconhecida na natureza \\
1962 & Utilização de zeólitas como catalisadores de craqueamento \\
1968 & A seletividade de forma nas zeólitas é descoberta \\
1982 & Wilson sintetiza uma série de peneiras moleculares de aluminofosfatos \\
1983 & A Enichem, na Itália, introduz a TS-1, a primeira peneira molecular redox \\
1985 & Conversão do metanol em gasolina: Processo Mobil com ZSM-5 \\
1986 & N. Herron (Du Pont) cria a peneira barco-na-garrafa (Co-salen+zeólita Y) \\
1988 & Davis sintetiza o VPI-5, uma peneira molecular com poros de $12 \AA$ \\
\hline
\end{tabular}

Seletividade de reagente:

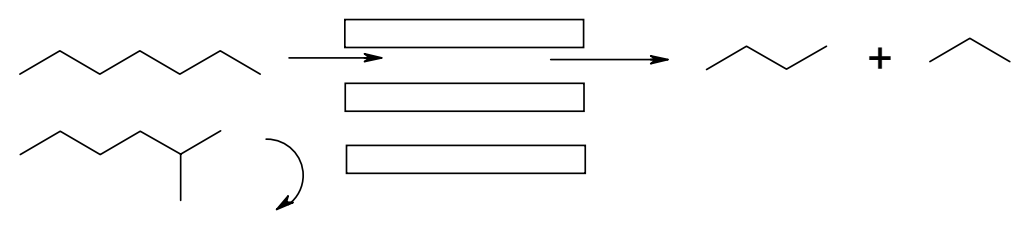

Seletividade de produto:

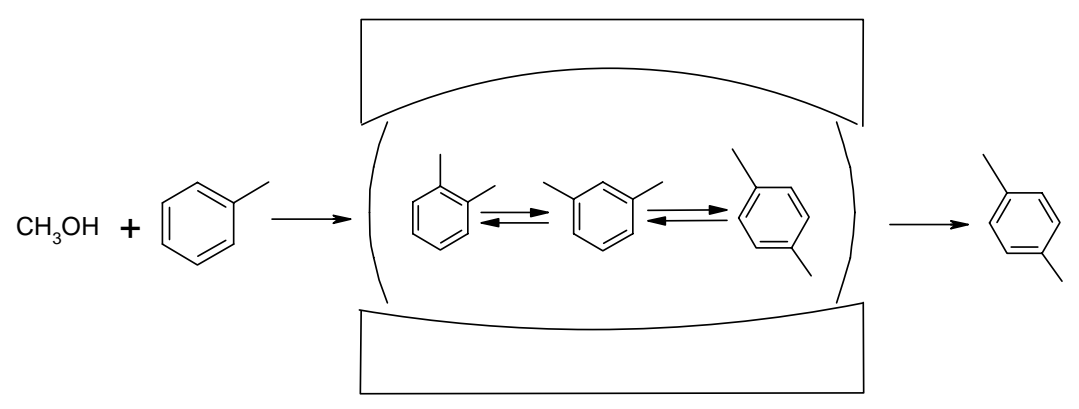

Seletividade do estado de transição:

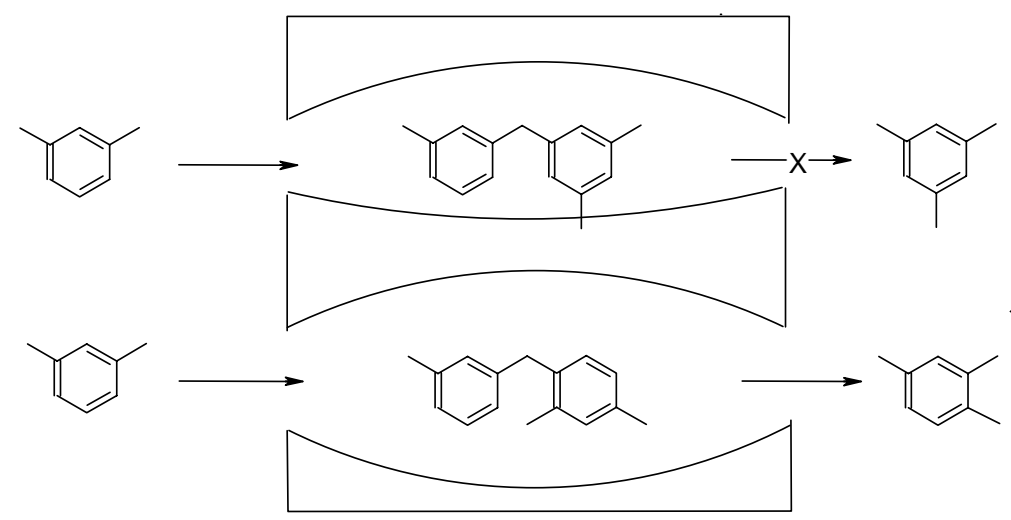

Figura 2. Tipos de seletividade com peneiras moleculares ${ }^{22}$. 
O fenômeno da seletividade nas zeólitas pode ser usado para conduzir uma reação catalítica na direção do produto desejado, evitando reações paralelas indesejadas.

De acordo com a Figura 3, a epoxidação do cicloocteno ocorre nos canais da zeólita $\beta$, (poros $=6 \times 7 \AA$ ), mas não há reação quando a TS-1, de poros menores (vide Tabela 2), é utilizada porque a olefina não chega a entrar nos canais ${ }^{23}$. Além dos tipos de seletividade discutidos acima, a introdução de substâncias quirais em zeólitas resulta na criação de sítios ativos estereoespecíficos ${ }^{24}$.

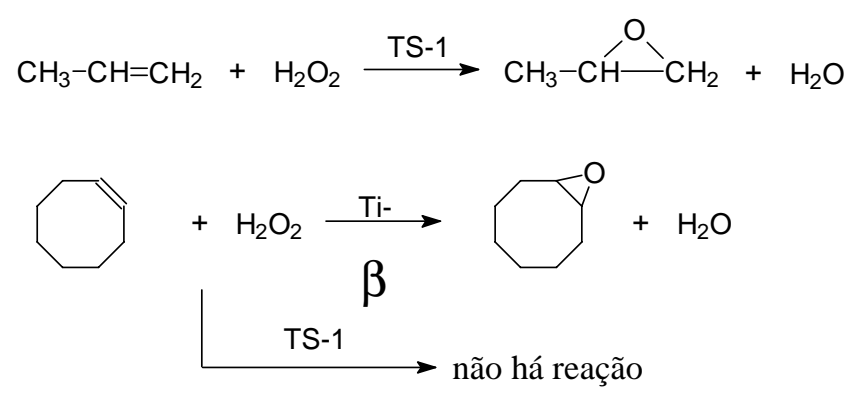

Figura 3. Seletividade proporcionada por zeólitas em oxidação catalítica ${ }^{23}$.

A terceira edição do Atlas of Zeolite Structure Types ${ }^{25}$ descreve 85 tipos diferentes de estruturas de zeólitas que podem ser encontradas com centenas de composições químicas distintas. Em 1998, o número de estruturas descritas já chegava a $105^{26}$. A Tabela 2 lista algumas peneiras moleculares micro- e mesoporosas e suas principais características.

Além das silicalitas e dos aluminossilicatos, uma das principais classes de peneiras moleculares microporosas são os aluminofosfatos, criados por pesquisadores da Union Carbide no início da década passada, que contêm somente alumínio, fósforo e oxigênio em sua estrutura ${ }^{13}$. Atualmente, existem mais de vinte estruturas de aluminofosfatos microporosos nas regiões de poros pequenos, médios, grandes e supergrandes. Entre estas, nove estruturas são análogas àquelas de zeólitas conhecidas, enquanto as demais são estruturas completamente novas, sem similares nem na natureza, nem entre as zeólitas previamente sintetizadas ${ }^{27}$.

\section{ESTRUTURA}

A estrutura das zeólitas é baseada em tetraedros de $\mathrm{TO}_{4}$
$(\mathrm{T}=\mathrm{Si}, \mathrm{Al}, \mathrm{P}$, etc.) que se ligam entre si através de um átomo de oxigênio comum para formar unidades básicas de construção (u.b.c.), como esquematizado na Figura 4.

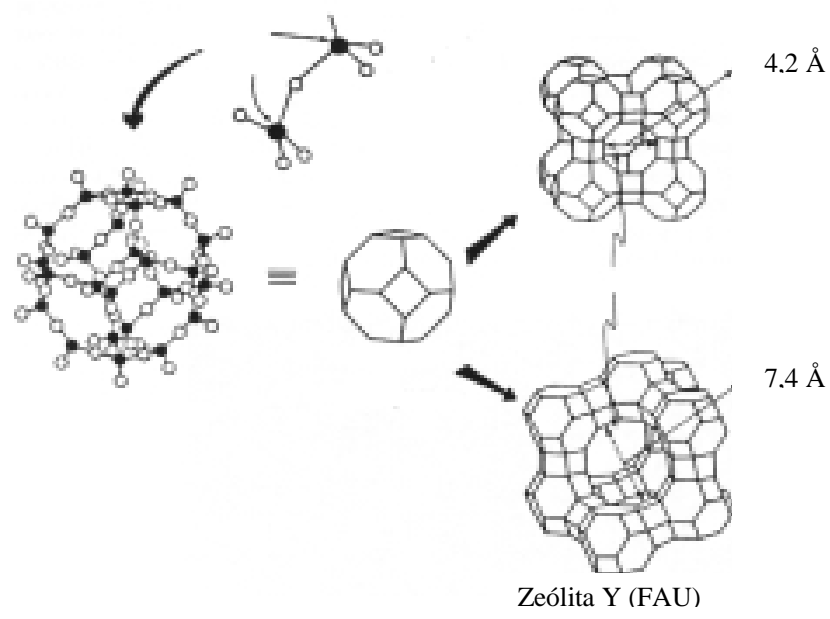

Figura 4. Gênese das estruturas FAU e LTA a partir de tetraedros de $\mathrm{TO}_{4}{ }^{28}$.

Os tetraedros seminais são formados por um átomo denominado $\mathrm{T}$ cercado de quatro átomos de oxigênio localizados nos vértices. Arranjos tridimensionais variados das unidades básicas de construção resultam nas superestruturas contendo os canais de dimensões moleculares que caracterizam as peneiras moleculares ${ }^{29}$. O sistema poroso pode ser uni-, bi- ou tridimensional. A dimensionalidade do sistema de canais pode determinar a susceptibilidade de uma zeólita à desativação. A mobilidade das moléculas reagentes no interior de uma zeólita contendo canais em todas as três direções é maior do que em um sistema unidimensional, e, portanto menor a possibilidade de bloqueio dos canais ${ }^{30}$.

A União Internacional de Química Pura e Aplicada (IUPAC) classifica as zeólitas utilizando um código de três letras baseado somente na estrutura, independente da composição química, como exemplificado na Tabela 2. Os microporos das zeólitas são classificados de acordo com o tamanho: poros pequenos $(<4 \AA)$, médios $(4-6 \AA)$, grandes (6-8 $\mathrm{A})$, ou supergrandes (> $8 \AA$ ). Peneiras moleculares com poros maiores que $20 \AA$, com paredes amorfas, são classificadas como mesoporosas ${ }^{25}$.

Tabela 2. Características dos poros de algumas peneiras moleculares ${ }^{2}$.

\begin{tabular}{|c|c|c|c|c|c|}
\hline $\begin{array}{l}\text { tamanho do } \\
\text { microporo }\end{array}$ & $\begin{array}{l}\text { diâmetro do } \\
\text { poro/A }\end{array}$ & nome comum & $\begin{array}{l}\text { símbolo } \\
\text { estrutural }\end{array}$ & $\underset{*}{\operatorname{dimensionalidade}}$ & $\begin{array}{l}\text { maior molécula } \\
\text { adsorvível }\end{array}$ \\
\hline pequeno & 4,1 & zeólita A & LTA & 3 & n-hexano \\
\hline médio & $\begin{array}{l}5,3 \times 5,6 \\
3,9 \times 6,3 \\
5,5 \times 6,2\end{array}$ & $\begin{array}{c}\text { TS-1, ZSM-5 } \\
\text { AlPO-11 } \\
\text { ZSM-12 }\end{array}$ & $\begin{array}{l}\text { MFI } \\
\text { AEL } \\
\text { MTW }\end{array}$ & $\begin{array}{l}3 \\
1 \\
1\end{array}$ & $\begin{array}{l}\text { cicloexano } \\
\text { cicloexano } \\
-\end{array}$ \\
\hline grande & $\begin{array}{l}7,3 \\
7,4 \\
\sim 6 \times \sim 7\end{array}$ & $\begin{array}{c}\text { AlPO-5 } \\
\text { zéolita } X, Y \\
\text { zeólita } \beta\end{array}$ & $\begin{array}{l}\text { AFI } \\
\text { FAU } \\
\text { BEA }\end{array}$ & $\begin{array}{l}1 \\
3 \\
3\end{array}$ & $\begin{array}{c}\text { neopentano } \\
\text { tributilamina } \\
-\end{array}$ \\
\hline $\begin{array}{l}\text { supergrande } \\
\text { mesoporoso }\end{array}$ & $\begin{array}{l}7,9 \times 8,7 \\
12,1 \\
13,2 \times 4,0 \\
15-100\end{array}$ & $\begin{array}{l}\text { AlPO-8 } \\
\text { VPI-5 } \\
\text { cloverita } \\
\text { MCM-41 }\end{array}$ & $\begin{array}{l}\text { AET } \\
\text { VFI } \\
\text { CLO }\end{array}$ & $\begin{array}{l}1 \\
1 \\
3 \\
1\end{array}$ & $\begin{array}{c}- \\
\text { triisopropilbenzeno } \\
- \\
-\end{array}$ \\
\hline
\end{tabular}

*Dimensionalidade $1=$ canais unidirecionais. 2 = canais cruzados. 3 = canais nas três direções $\mathrm{x}, \mathrm{y}$ e $\mathrm{z}$ 


\section{COMPOSIÇÃO QUÍMICA}

Em zeólitas, os centros dos tetraedros de $\mathrm{TO}_{4}$ são ocupados por átomos de silício e de alumínio numa razão $\mathrm{Si}$ : $\mathrm{Al}$ que pode variar de $1: 1$ até $\infty: 1$, de acordo com a regra de Löwenstein ${ }^{31}$. Em aluminofosfatos, a razão Al:P é igual a 1, ou um pouco maior se houver defeitos na estrutura. A acidez nos aluminossilicatos pode ser controlada manipulando-se a razão $\mathrm{Si}$ : Al; sendo possível obter zeólitas com uma acidez de Brønsted comparável à do ácido sulfúrico. Por outro lado, aluminofosfatos apresentam baixa acidez por causa de sua estrutura neutra ${ }^{30}$. Na Tabela 3, a composição e propriedades das principais classes de peneiras moleculares microporosas são comparadas.

\section{Polaridade}

Quando zeólitas são usadas como catalisadores heterogêneos em meio líquido, o solvente da reação exerce influência sobre o tipo de substrato que terá acesso ao sítio ativo no interior dos canais e cavidades. Nesse caso, a zeólita funciona como um "solvente dentro de um solvente", extraindo da fase líquida as moléculas de substrato somente se houver compatibilidade entre as características físico-químicas da zeólita com o substrato ${ }^{30}$. Portanto, além do tamanho de poro apropriado, as afinidades por água (hidrofilicidade) do substrato e da zeólita devem ser coincidentes: um substrato altamente polar não entraria nos poros de uma zeólita $\mathrm{Y}$ desaluminada, por exemplo $^{32}$. Esta característica pode ser considerada análoga à do manto protéico das enzimas naturais, que identifica qual o substrato terá acesso ao sítio ativo com seletividade absoluta. Num exemplo prático, a titanossilicalita, cujos poros são hidrofóbicos, é apropriada para oxidação de substratos apolares como o cicloexano, usando peróxido de hidrogênio como oxidante $^{33}$. Nesse caso, extremamente auspicioso, tanto o substrato apolar $\left(\mathrm{C}_{6} \mathrm{H}_{6}\right)$ quanto o oxidante pouco polar $\left(\mathrm{H}_{2} \mathrm{O}_{2}\right)$ são seletivamente adsorvidos pelos canais hidrofóbicos da TS-1, onde se transformam nos produtos água, cetona e álcool. Estes, por sua vez, são expulsos dos canais porque são compostos polares; dessa forma, a interação entre a polaridade da zeólita e dos reagentes e produtos funciona como uma bomba molecular, sugando moléculas de substrato para os sítios ativos no interior da zeólita, e expelindo os produtos, como ilustrado na Figura 5.

\section{MODIFICAÇÕES EM ZEÓLITAS}

Zeólitas são catalisadores eficientes porque a aproximação forçada entre moléculas reagentes sob a influência dos fortes potenciais eletrostáticos existentes no interior dos canais e cavidades provoca o abaixamento da energia de ativação necessário ao fenômeno da catálise ${ }^{34}$. Além disso, o acesso de moléculas do solvente ao sítio ativo é dificultado porque este se localiza

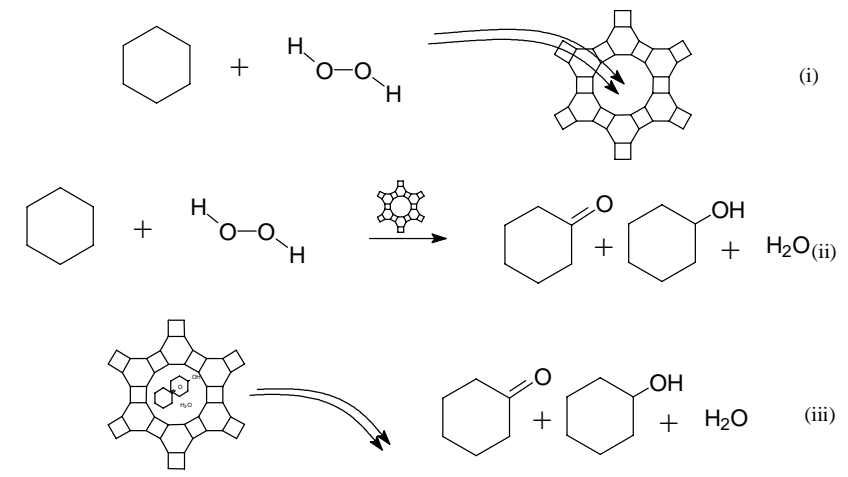

Figura 5. Transporte com "bomba molecular": (i) reagentes apolares são adsorvidos por uma zeólita hidrofóbica; (ii) a reação catalítica ocorre no interior das cavidades e, finalmente, (iii) os produtos polares são expelidos da zeólita.

dentro de uma cavidade de dimensões moleculares, de forma a isolar parcialmente as moléculas dos reagentes no interior sítio ativo, em condições semelhantes às de reações em fase gasosa, que são geralmente mais rápidas do que reações em solução ${ }^{35}$.

As zeólitas podem ser modificadas segundo estratégias variadas de forma a melhorar substancialmente sua atividade e seletividade catalíticas. A modificação de zeólitas pela introdução de metais de transição dá origem às chamadas "peneiras redox". Estes compostos, que, em tese, possuiriam atividade e mecanismo comparáveis àqueles encontrados em enzimas, podem ser considerados, grosso modo, "enzimas minerais" ou "zeozimas" 36 . Os tipos de modificações a que zeólitas podem ser submetidas são discutidos abaixo.

\section{Troca iônica}

As estruturas dos aluminossilicatos e dos silicaluminofosfatos possuem carga negativa por causa do desbalanceamento entre os números de oxidação dos átomos T. Como as cargas negativas remanescentes são compensadas por cátions trocáveis, é possível introduzir espécies catiônicas de metais redox por um simples processo de troca iônica ${ }^{30}$. A troca iônica pode ser completa ou parcial. Zeólitas adsorvem preferencialmente determinados cátions de acordo com o tamanho do poro e com o caráter hidrofílico específico ${ }^{37}$. A localização dos sítios trocáveis no caso da estrutura faujasita é mostrada na Figura 6.

Caso o volume da esfera de coordenação dos cátions hidratados a serem introduzidos impeça a entrada no sistema poroso, é possível recorrer à troca iônica em estado sólido como alternativa. Nesse caso, a trituração do sal do metal de transição com a zeólita desidratada com a ajuda de um almofariz, seguida de um tratamento térmico, é suficiente para que a troca iônica aconteça. Algumas vantagens justificam o procedimento da troca no estado sólido em detrimento do método convencional em

Tabela 3. Composição e propriedades de zeólitas e análogos ${ }^{30}$.

\begin{tabular}{lll}
\hline peneira molecular & composição & propriedades \\
\hline aluminossilicatos & $\left(\mathrm{Si}^{\mathrm{IV}}-\mathrm{O}-\mathrm{Al}^{\mathrm{III}}-\mathrm{O}-\mathrm{Si}^{\mathrm{IV}}\right)^{-}$ & carga negativa na estrutura, hidrofílica, têm sítios ácidos e de troca iônica \\
& $\mathrm{H}^{+}$ou M $\mathrm{M}^{\mathrm{n}}$ & \\
silicalitas & $\mathrm{Si}^{\mathrm{IV}}-\mathrm{O}-\mathrm{Si}^{\mathrm{IV}}-\mathrm{O}-\mathrm{Si}^{\mathrm{IV}}$ & não têm sítios ácidos nem de troca iônica, estrutura neutra, hidrofóbica \\
aluminofosfatos & $\mathrm{Al}^{\mathrm{III}}-\mathrm{O}-\mathrm{P}^{\mathrm{V}}-\mathrm{O}-\mathrm{Al}^{\mathrm{III}}$ & não têm sítios ácidos nem de troca iônica, estrutura neutra, hidrofílica \\
Silicalumino- & & \\
fosfatos (SAPO) & $\left(\mathrm{Si}^{\mathrm{IV}}-\mathrm{O}-\mathrm{Al}^{\mathrm{III}}-\mathrm{O}-\mathrm{P}^{\mathrm{V}}\right)^{-}$ & carga negativa na estrutura, hidrofílica, têm sítios ácidos e de troca iônica \\
\hline
\end{tabular}




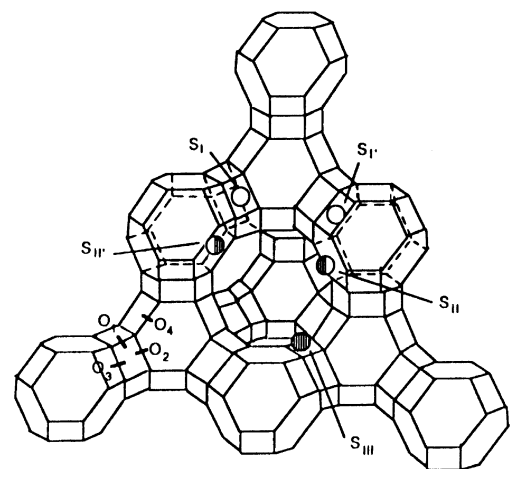

Figura 6. Os sítios catiônicos trocáveis da faujasita (zeólita X ou $Y)^{38}$.

solução para a introdução de cátions metálicos em zeólitas: (i) no estado sólido não é necessário manusear grandes volumes de soluções salinas; (ii) o descarte de soluções de sais é evitado, diminuindo danos ao meio ambiente; (iii) podem ser introduzidos cátions metálicos, em casos que a troca iônica em solução seria impedida pelo volume da esfera de solvatação do cátion ${ }^{39}$.

\section{Barco-na-garrafa (ship in a bottle)}

A encapsulação de metais de transição, ou compostos organometálicos destes, nas cavidades de zeólitas produz materiais chamados barco-na-garrafa (do inglês, ship in a bottle) com enorme potencial para uso em catálise. Para encapsular um composto dentro de uma zeólita, a molécula deve se formar no interior da supercavidade a partir de precursores menos volumosos, que são introduzidos seqüencialmente através dos canais, da mesma forma que as partes de um barquinho de brinquedo podem ser introduzidas pelo gargalo e montadas no interior de uma garrafa ${ }^{4}$. O termo ship in a bottle foi criado por Norman Herron no início da década de $1980^{40}$. Ele promoveu a complexação de íons de cobalto com uma base de Schiff (salen) como ligante no interior da zeólita $\mathrm{Y}$ e sugeriu que o composto poderia ser usado no transporte de oxigênio molecular ${ }^{41}$. Além da estratégia de Herron, outras estratégias de síntese destes compostos têm sido utilizadas. Tanto se pode realizar a síntese do ligante e subsequente complexação no interior da zeólita; quanto sintetizar a própria zeólita usando o composto a ser encapsulado como direcionador de estrutura (vide Figura 10 abaixo) ${ }^{30}$.

Encapsulação do tipo barco-na-garrafa tem sido preferencialmente feito com a zeólita Y por causa da supercavidade de $13 \AA$ A , acessível por janelas formadas por anéis de 12 membros cujo diâmetro é 7,4 Å. A Figura 7 (c) mostra a ftalocianina de ferro encapsulada na zeólita Y.

Contudo há vários exemplos ${ }^{42,43}$ de peneiras moleculares barco-na-garrafa preparadas com o VPI-5, que possui canais retos. A estabilidade desses materiais é baseada no confinamento físico da molécula encapsulada dentro da peneira-a espécie encapsulada tem dimensões comparáveis (ou pouco maiores) à do canal ou cavidade. Além disso, a retenção eletrostática e imobilização por baixa solubilidade também são importantes para manutenção da estabilidade da espécie encapsulada na zeólita barco-na-garrafa. Complexos metálicos como ftalocianinas, polipiridinas ou bases de Schiff têm sido mais utilizadas como hóspede (guest) em compostos barco-nagarrafa por causa de sua resistência à oxidação ${ }^{30}$.

\section{Dopagem ou Substituição isomórfica}

Peneiras redox são produzidas pela introdução de cátions de metais de transição que substituem isomorficamente uma fração dos átomos $\mathrm{T}$ da estrutura, num processo de dopagem, produzindo sítios isolados contendo o metal de transição no produto final, como mostra a Figura 8. a
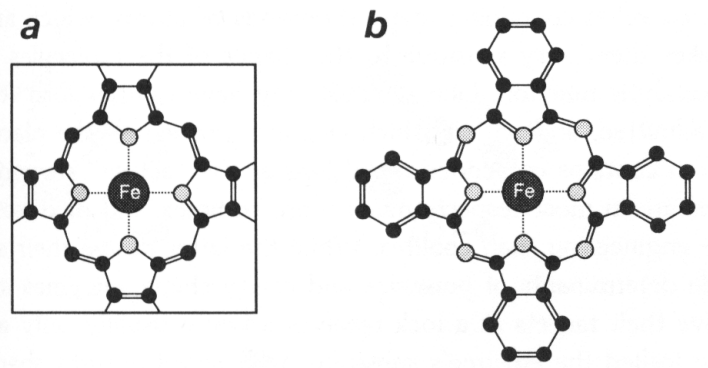

c

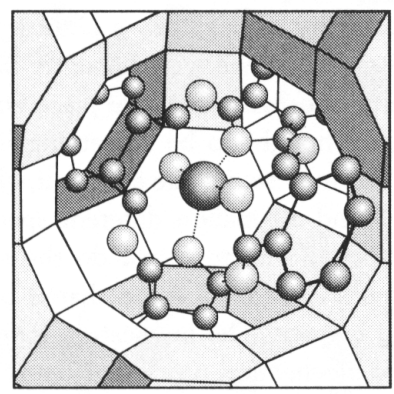

Figura 7. A ftalocianina de $\mathrm{Fe}$ (b) é o análogo sintético da enzima citocromo P450 (a); introduzido na zeólita $Y$, forma um composto barco-na-garrafa $(c)^{4}$.

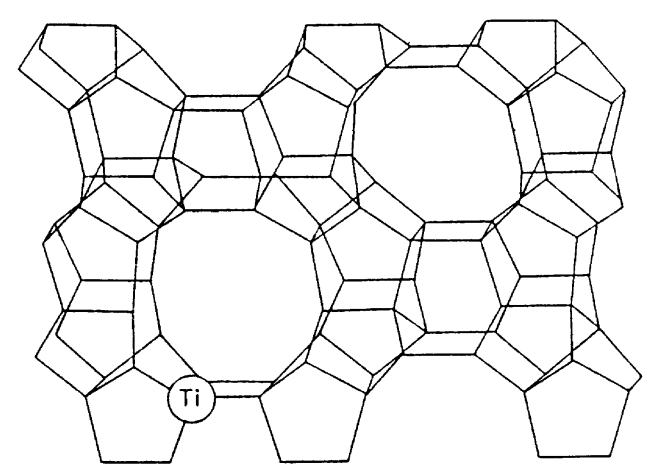

Figura 8. Titanossilicalita (TS-1), a primeira peneira redox, contendo átomos de titânio isomorficamente substituídos na rede cristalina ${ }^{44}$.

Peneiras moleculares redox devem possuir idealmente uma quantidade limitada de sítios ativos contendo um íon metálico, que se encontram espalhados no interior da estrutura cristalina microporosa. A reação catalisada deve acontecer nesses sítios ativos no interior dos microporos, de acordo com o esquema mostrado na Figura $9^{44}$.

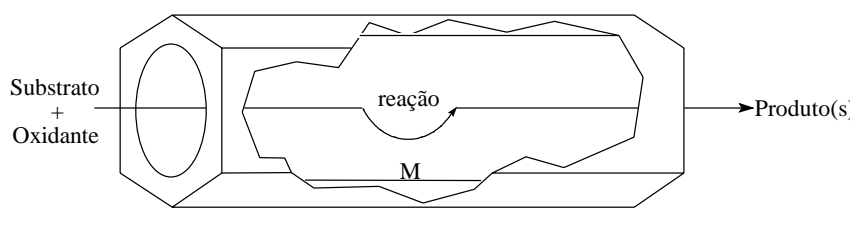

sítio ativo isolado

Figura 9. Transporte e reação em canais monodimensionais ${ }^{44}$.

O fósforo pode se incorporar nos aluminossilicatos naturais, porém sinteticamente, é mais comum incorporar silício em aluminofosfatos, para formar os silicaluminofosfatos. A síntese desses materiais resulta em estruturas encontradas em aluminossilicatos e aluminofosfatos, além de três novas estruturas, somente obtidas em presença de silício ${ }^{27}$. Além do silício, treze 
outros elementos podem ser encontrados na estrutura dos aluminofosfatos: $\mathrm{Li}^{+}, \mathrm{Be}^{2+}, \mathrm{Mg}^{2+}, \mathrm{Co}^{2+}, \mathrm{Fe}^{2+}, \mathrm{Mn}^{2+}, \mathrm{Zn}^{2+}, \mathrm{B}^{3+}, \mathrm{Ga}^{3+}$, $\mathrm{Fe}^{3+}, \mathrm{Ge}^{4+}, \mathrm{Ti}^{4+}$ e $\mathrm{As}^{5+}$, ou combinações de até cinco desses elementos simultaneamente ${ }^{27}$.

De acordo com a teoria da ligação química de Pauling ${ }^{45}$, a substituição de um átomo metálico cercado de quatro átomos de oxigênio no retículo cristalino da zeólita somente será possível se a razão entre o raio do cátion metálico e o raio do ânion de oxigênio for maior que 0,225 e menor que 0,414 . Na prática, observa-se que a incorporação de cátions pode ocorrer mesmo se a razão $\mathrm{r}\left(\mathrm{M}^{+}\right) / \mathrm{r}\left(\mathrm{O}^{2-}\right)$ exceder esse limite superior. A experiência também revela que mudanças na esfera de coordenação do cátion substituinte podem ser causadas por variações no estado de oxidação que resultam de processos de calcinação necessários para eliminação do direcionador de estrutura orgânico e da água remanescente na zeólita recém-sintetizada ${ }^{30}$.

No caso de peneiras redox contendo crômio, o material recém-sintetizado geralmente contém $\mathrm{Cr}$ (III), que passa a $\mathrm{Cr}(\mathrm{VI})$ depois de calcinado a $400-500^{\circ} \mathrm{C}$. Como o $\mathrm{Cr}(\mathrm{VI})$ necessariamente possui duas ligações crômio-oxigênio fora do retículo cristalino, a peneira calcinada terá crômio em sítios defeituosos. De forma semelhante comporta-se o vanádio que passa do estado de oxidação $4+$ na peneira recém-sintetizada para 5+ depois de calcinada. Em peneiras redox, tanto cobalto quanto manganês encontram-se no estado de oxidação $2+$ no material recém-sintetizado e 3+ depois da calcinação. Nesses dois casos, a substituição isomórfica é mantida mesmo depois da calcinação ${ }^{30}$. A calcinação seguida de ativação in vacuo não causou mudança no estado de oxidação, mas a migração do ferro para fora das posições reticulares foi observada na $\mathrm{Fe}$ (III)-silicalita ${ }^{46}$. O titânio, por sua vez, não varia do estado de oxidação $4+$.

Via de regra, peneiras moleculares são sintetizadas a partir de géis aquosos contendo fontes dos elementos estruturais ( $\mathrm{Al}$, $\mathrm{Si}, \mathrm{P}$, etc.), um agente mineralizante $\left(\mathrm{F}^{-}, \mathrm{OH}^{-}\right)$e o agente direcionador da estrutura desejada (uma amina orgânica ou um sal de amônio quaternário). Os géis são cristalizados em autoclaves a temperaturas entre 100 e $200^{\circ} \mathrm{C}$, sob pressão autógena, por períodos que podem variar desde algumas horas até várias semanas. O sólido obtido, depois de lavado para eliminação de resquícios de gel não cristalizado, deve ser calcinado entre 500 e $600^{\circ} \mathrm{C}$ para queima do direcionador de estrutura ainda presente no interior dos canais. Um dos prováveis mecanismos da síntese hidrotérmica de zeólitas, chamado "mão-naluva" (hand-in-the-glove), está esquematizado na Figura $10^{47}$.

$\mathrm{O}$ mecanismo consiste na organização de tetraedos de $\mathrm{TO}_{4}$ segundo uma dada topologia em torno do direcionador de estrutura orgânico durante as etapas de formação ou nucleação do gel, produzindo a unidade seminal a partir da qual o retículo cristalino iniciará seu crescimento. O direcionador de estrutura tem pelo menos duas funções na síntese de zeólitas. Além de definir a topologia específica, em que fatores como densidade de carga, forma e volume da molécula são determinantes; o direcionador também atua para moderar o $\mathrm{pH}$ do gel de síntese- portanto tanto a solubilidade quanto o $\mathrm{pK}_{\mathrm{b}}$ da amina são fatores a ser considerados na escolha do direcionador mais apropriado para cada estrutura ${ }^{48}$.

Casos em que existe um único ajuste exato "mão-dentro-daluva" entre o direcionador e o retículo da zeólita, como o mostrado na Figura 11, são raros. Uma dada topologia geralmente pode ser sintetizada com o uso de vários direcionadores diferentes e a maioria dos direcionadores pode ser utilizada para síntese de mais de uma estrutura ${ }^{49}$. Além disso, existem relatos de síntese do aluminofosfato VPI-5 e da silicalita ZSM12 a partir de géis puramente inorgânicos ${ }^{49,50}$.

\section{Modificação pós-síntese}

Ao contrário da síntese hidrotérmica, a modificação pós-síntese permite a preparação de peneiras redox a partir de peneiras
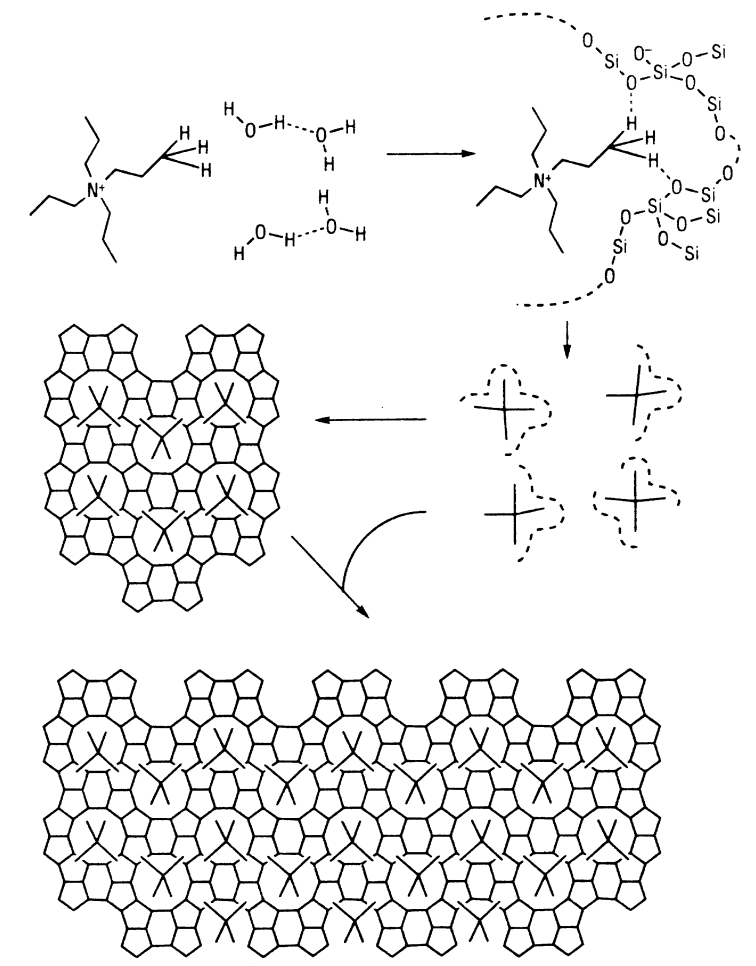

Figura 10. Mecanismo "mão-na-luva" da síntese de zeólitas 47.

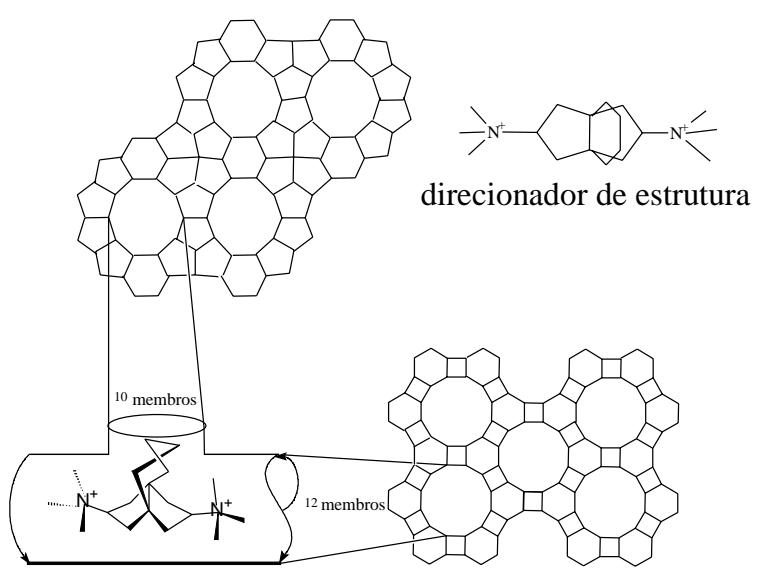

Figura 11. Um exemplo de ajuste entre o direcionador orgânico de estrutura e os canais assimétricos da zeólita SSZ-26 ${ }^{48}$.

moleculares disponíveis comercialmente, cujas propriedades já se encontram otimizadas para utilização em catálise. A modificação pós-síntese tem sido utilizada principalmente para alterar a acidez de zeólitas pela modificação da razão $\mathrm{Si} / \mathrm{Al}$ através do tratamento com vapor de $\mathrm{SiCl}_{4}{ }^{30}$. Além disso, o alumínio reticular de uma zeólita pode ser substituído por titânio através de tratamento com vapor de $\mathrm{TiCl}_{4}$. No entanto, borossilicatos são mais apropriados a esse tipo de modificação porque átomos de boro podem ser facilmente removidos do retículo sob condições brandas. Em seguida, os ninhos de silanóis resultantes da remoção dos átomos de boro podem ser substituídos por titânio pela exposição a vapor de cloreto de titânio ${ }^{51}$.

\section{LIXIVIAÇÃO EM PENEIRAS REDOX}

A estabilidade da ligação química entre os metais introduzidos e o retículo cristalino das peneiras é um dos principais entraves à aplicação de peneiras moleculares isomorficamente 
substituídas como catalisadores heterogêneos em fase líquida. Como foi discutido acima, os dois fatores que influenciam a substituição do alumínio ou fósforo por metais de transição são: (i) a compatibilidade entre o raio iônico do metal substituinte e o oxigênio; e (ii) a geometria assumida pelo metal substituinte. A incompatibilidade entre o retículo e o metal substituinte resulta no aparecimento de falhas estruturais no cristal, e mais grave, lixiviação dos metais substituintes para o meio reacional durante a reação catalítica em fase líquida.

Sheldon et al. ${ }^{51}$ afirmam que existem três alternativas no problema da lixiviação dos metais substituídos em peneiras redox; cada uma com consequiências específicas: (i) o metal lixivia, mas não é ativo em solução; (ii) o metal lixivia e se torna um catalisador ativo em solução; (iii) o metal não lixivia e a catálise observada é de natureza heterogênea. A quarta possibilidade aventada - o metal não lixivia, mas não se observa atividade-é claro que não interessa. A experiência mostra que as peneiras redox contendo titânio isomórfico se encaixam na categoria (i) ou (iii). Como Ti(IV) homogêneo não é um catalisador ativo para epoxidação com peróxido de hidrogênio, a alta atividade nesse tipo de reação observada com a titanossilicalita (TS-1) e com outras peneiras redox contendo titânio pode ser considerada de natureza heterogênea. Há estudos mostrando que crômio ${ }^{52}$ e vanádio ${ }^{53}$ lixiviam dos aluminofosfatos quando usados em oxidações em fase líquida, podendo ser incluídos na categoria (ii). A lixiviação do cobalto incorporado em CoAPO-5 e CoAPO-11 foi observada tanto na autoxidação de $p$-cresol a $p$-hidroxibenzaldeído ${ }^{54}$, quanto na autoxidação de cicloexano ${ }^{55}$. Portanto, até prova em contrário, somente as peneiras redox contendo titânio isomórfico podem ser consideradas catalisadores heterogêneos estáveis face ao fenômeno da lixiviação quando usadas em oxidações em fase líquida.

\section{CATÁLISE COM ZEÓlITAS}

A utilização de zeólitas como catalisadores ácidos sólidos é uma tecnologia promissora para o futuro, mas já existem processos comerciais e plantas piloto utilizando esses catalisadores por causa das vantagens de que mostram em relação aos tradicionais catalisadores ácidos homogêneos ${ }^{56}$. A acidez da zeólita se encontra no seu interior, portanto pode ser manuseada muito mais facilmente do que, por exemplo, o ácido sulfúrico, um líquido altamente corrosivo. Um derramamento de uma carga de zeólitas numa rodovia traria conseqüências inócuas comparado a um acidente equivalente com ácido sulfúrico. Além disso, alguns tipos de zeólita possuem acidez 10 milhões de vezes mais forte do que o ácido sulfúrico concentrado ${ }^{57}$.

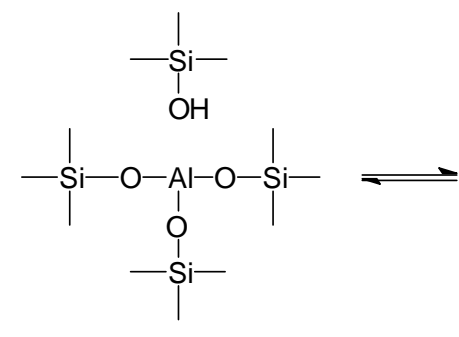

Sítio de Lewis

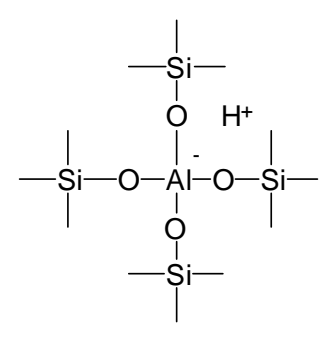

Sítio de Brønsted
Figura 12. Sítios ácidos em zeólitas ${ }^{34}$.

Além de realizar a separação do vários componentes do petróleo por destilação, a indústria do petróleo tem como objetivo reformar o produto destilado de forma a produzir a variedade de produtos do petróleo: (a) hidrocarbonetos $\mathrm{C}_{1}-\mathrm{C}_{4}$; (b) gasolina; (c) nafta; (d) querosene; e (e) gasóleo leve ${ }^{34}$. A indústria do petróleo depende basicamente de catalisadores contendo zeólitas. O uso pioneiro de zeólitas no craqueio de petróleo ainda continua sendo a mais importante aplicação prática desses materiais. Outros processos industriais catalisados por zeólitas são o hidrocraqueamento, isomerização de xileno, alquilação de benzeno, e a produção de gasolina a partir de metanol. Atualmente, mais de um terço de toda a gasolina consumida na Nova Zelândia é produzida dessa forma ${ }^{29}$.

\section{Refino de petróleo craqueamento catalítico em leito fluidizado (FCC)}

Na produção de gasolina, é necessário quebrar as moléculas maiores de hidrocarbonetos $\left(\mathrm{C}_{1}-\mathrm{C}_{6}\right)$ em um processo chamado craqueamento. $\mathrm{O}$ processo é feito num leito catalítico fluido, onde o petróleo é misturado com o catalisador em pó formando um slurry (suspensão de sólido em líquido) que é injetado num reator mantido a cerca de $500^{\circ} \mathrm{C}^{34}$.

\section{Hidrotratamento}

\section{Hidrogenação/desidrogenação}

Além dos sítios ácidos, é necessário introduzir um segundo tipo de sítio que funciona como centro ativo para a reação de hidrogenação. Um grande número de compostos podem ser introduzidos nas zeólitas para funcionar como centros ativos: (i) metais nobres $(\mathrm{Pd}, \mathrm{Pt} . .$.$) , (ii) metais de transição (Ni, Co...),$ (iii) óxidos metálicos $(\mathrm{ZnO}, \mathrm{CuO}, \mathrm{NiO} \ldots)$, sulfetos metálicos (NiS, Co/MoS), e complexos metálicos. Estes componentes podem ser introduzidos por métodos que incluem: mistura física do componente, impregnação da zeólita, troca iônica, adsorção, como discutido acima ${ }^{37}$.

\section{Hidrocraqueamento}

O hidrocraqueamento é um processo industrial para transformar em gasolina e outros combustíveis líquidos as frações mais pesadas resultantes da destilação do petróleo. Geralmente, os catalisadores consistem de um ácido sólido (zeólita, sílica-alumina amorfa, ou alumina), contendo um componente hidrogenante (Pt, Pd, etc.). As zeólitas mais usadas neste processo são as faujasitas, mordenitas ou erionitas sintéticas. No entanto, ultimamente estas têm sido substituídas por zeólitas contendo alto teor de silício, como a zeólita Y desaluminizada ou a Y ultra-estável (US-Y). Também são incorporados aos catalisadores zeólitas de alto teor de sílica como a ZSM-5. A reação catalítica de hidrocraqueamento é feita entre 250 e $430^{\circ} \mathrm{C}$ sob pressão de hidrogênio $(15-150 \text { bar })^{34}$.

\section{Oxidação seletiva}

A oxidação parcial de alcanos de forma seletiva é um dos principais problemas enfrentados pela indústria química. A oxidação de cicloexano catalisada por naftenato de cobalto é realizada em grande escala no Brasil pela Nitrocarbono S.A. (45.000 ton/ano em Camaçari, Ba) para produzir cicloexanona e cicloexanol. Estes produtos são novamente oxidados até ácido adípico que, por sua vez, é utilizado na produção de Nylon. Atualmente, os catalisadores sendo pesquisados para a melhoria do processo de oxidação do cicloexano incluem sistemas homogêneos (e.g. sistemas GIF) ${ }^{58}$, zeólitas contendo complexos metálicos barco-na-garrafa (e.g. Fe-ftalocianina, vide Figura 7$)^{59}$,ou aluminofosfatos contendo metais de transição introduzidos isomorficamente ${ }^{60}$.

A epoxidação de olefinas com água oxigenada pode ser catalisada com a titanossilicalita-1 (TS-1, vide Figura 8). A TS-1 também promove a hidroxilação de fenol a catecol e hidroquinona. Uma planta com capacidade de 10.000 toneladas por ano está em operação desde $1986^{30}$. 


\section{CONCLUSÃO}

Já é possível afirmar que as zeólitas são os catalisadores mais importantes da indústria química e petroquímica. A potencialidade dessa classe de materiais de crescente importância ainda pode ser amplamente explorada. Zeólitas e outras peneiras moleculares microporosas de estrutura análoga podem ser modificadas segundo métodos que incluem: troca iônica, encapsulação de espécies ativas, substituição isomórfica durante a cristalização ou após a síntese do material. Além do tamanho de poro apropriado, a utilização em catálise de uma dada zeólita deve ser avaliada também pela afinidade entre a polaridade do solvente, reagente e produto com a composição química do material microporoso. A lixiviação do metal oxirredutor é o principal entrave no uso de peneiras redox como catalisadores para oxidação de hidrocarbonetos em fase líquida.

\section{AGRADECIMENTOS}

Os autores agradecem à Profa. Regina Buffon pela revisão do manuscrito; ao CNPq, FAPESP e FAPERJ pelo auxílio financeiro.

\section{REFERÊNCIAS}

1. Thomas, J. M.; Angew. Chem. Int. Ed. Engl. 1994, 33, 913.

2. Roland, E.; Kleinschmit, P.; [in] Ullmann's Encyclopedia of Industrial Chemistry, 5a. ed., vol. A28 (B. Elvers e S. Hawkins, eds.) VCH, Weinheim, 1996, 476.

3. Flanigen, E. M.; Stud. Surf. Sci. Catal. 1991, 58, 13.

4. Ball, P.; Designing the Molecular World - Chemistry at the Frontier, Princeton University Press, Princeton, 1994.

5. Breck, D. W.; Zeolite Molecular Sieves, Wiley, Nova Iorque, 1974.

6. Corma, A.; Chem. Rev. 1997, 97, 2373.

7. Sheldon, R. A. [in] Grasselli et al. (eds.), 3rd World Congress on Oxidation Catalysis, Elsevier, Amsterdã, 1997.

8. Figueiredo, J. L.; Ribeiro, F. R.; Catálise Heterogênea, Fund. Calouste Gulbenkian, Lisboa, 1987.

9. Chen, N. Y.; Garwood, W. E.; Dwyer, F. G.; Shape Selective Catalysis in Industrial Applications, Marcel Dekker, Nova Iorque, 1989.

10. Sheldon, R.A.; Dakka, J.; Catal. Today 1994, 19, 215.

11. Sheldon, R.A.; Curr. Opin. Solid State \& Mat. Sci. 1996, $1,101$.

12. Davis, M. E.; Chem.-Eur. J. 1997, 11, 1745.

13. Wilson, S. T.; Lok, B. M.; Messina, C. A.; Cannan R. T.; Flanigen, E. M.; J. Am. Chem. Soc. 1982, 104, 1146.

14. Davis, M. E.; Saldarriaga, C.; Montes, C.; Garces J.; Crowder, C.; Nature 1988, 331, 698.

15. Estermann, M.; McCusker, L. B.; Baerlocher, C.; Merrouche, A.; Kessler, H.; Nature 1991, 352, 320.

16. Chen, J.; Jones, R. H.; Natarajan, S.; Hursthouse M. B.; Thomas, J. M.; Angew. Chem. Int. Ed. Engl. 1994, 33, 639.

17. Olson, D. H.; Haag, W.O.; Lago, R.M.; J. Catal. 1980, 61, 390.

18. Corma, A. [in] Zeolite Microporous Solids: Synthesis Structure and Reactivity, NATO ASI Series, 352, Kluwer Academic, Holanda, 1992.

19. Gianetto, G; Zeolitas: Caracteristicas, Propriedades y Aplicaciones Industriales, Ed. Caracas, 1990.

20. Weisz, P. B.; Frilette, V. J.; J. Phys. Chem. 1960, 64, 382.

21. Csicsery, S.M.; Pure Appl. Chem. 1986, 58, 841.

22. Smart, L.; Moore, E.; Solid State Chemistry, An Introduction, Chapman \& Hall, Londres, 1992.

23. Davis, M. E.; Acc. Chem. Res., 1993, 26, 111.

24. Hutchings, G. J.; Wells, R.; Feast, S.; Siddiqui, M. R. H.; Willock, D. J.; King, F.; Rochester, C. H.; Bethell D.; Bulman Page, P. C.; Catal. Letters 1997, 46, 249.
25. Meier, W. M.; Olson, D. H.; Atlas of Zeolite Structure Types, 3a. ed., Butterworth-Heinemann, Londres, 1992.

26. Klinowski, J; Cur. Opin Solid State \& Mat. Sci. 1998, 3, 79 .

27. Pastore, H. de O.; Quim. Nova 1996, 19, 372.

28. Thomas, J. M.; Angew. Chem. Int. Ed. Engl., 1988, 27, 1673.

29. Ball, P.; Made to Measure: new materials for the 21st century, Princeton University Press, Princeton, 1997.

30. Arends, I. W. C. E.; Sheldon, R. A.; Wallau, M.; Schuchardt, U.; Angew. Chem. Int. Ed. Engl. 1997, 36, 1144.

31. Gates, B.; Catalytic Chemistry, John Wiley \& Sons, Nova Iorque, 1992.

32. Bein, T; A.C.S. Sym. Ser., 1992, 499, 274.

33. Spinacé, E. V.; Pastore, H. O.; Schuchardt, U.; J. Catal. 1995, 157, 631.

34. Bond, G. C.; Heterogeneous Catalysis: Principles and Applications, 2nd ed, Clarendon, Oxford, 1987.

35. Sheldon, R. A.; Top. Curr. Chem., 1993, 164, 21.

36. Sheldon, R. A.; Chen, J. D.; Dakka, J.; Neeleman, E.; [in] New Developments in Selective Oxidation, Elsevier Publishers, Amsterdã, 1993; G.1-1.

37. Nagy, J. B.; Bodart, P.; Hannus, I.; Kiricsi, I.; Synthesis, characterization and use of zeolitic microporous materials, DecaGen Ltd Hungary, 1998.

38. Dooryhee, E.; Catlow, R. A.; Couves, J. W.; Maddox, P. J.; Thomas, J. M.; Greaves, G. N.; Steel, A. T.; Townsend, R. P.; J. Phys. Chem. 1991, 95, 4514.

39. Karge, H. G.; Stud. Surf. Sci. Catal. 1997, 105, 1901.

40. Herron, N.; Inorg. Chem. 1986, 25, 4714.

41. Luna, F. J.; Dissertação de Mestrado, Ibaraki University, Mito, Japão, 1993.

42. Passoni, L.C.; Luna, F.J.; Wallau, M.; Buffon, R.; Schuchardt, U; J. Mol. Catal. A: Chemical 1998, 132, 1822.

43. Parton, R.; Uytterhoeven, L.; Jacobs, P.A.; Stud. Surf. Sci. Catal. 1991, 59, 395.

44. Haanepen, J. M.; Tese de Doutorado, Technische Universiteit Eindhoven, Holanda, 1996.

45. Pauling, L; The Nature of the Chemical Bond, 3rd ed., Cornell University Press, Ithaca, 1960, cap. 3

46. Bordiga, S.; Buzzoni, R.; Geobaldo, F.; Lamberti, C.; Giamello, E.; Zecchina, A.; Leofanti, G.; Petrini, G.; Tozzola, G.; Vlaic, G.; J. Catal. 1996, 158, 486.

47. Davis, M. E.; Katz, A.; e Ahmad, W. R.; Chem. Mater. 1996, 8, 1820 .

48. Davis, M. E.; Chemtech 1994, 22.

49. Wilson, S. T.; Stud. Surf. Sci. Catal. 1991, 58, 137.

50. Duncan, B.; Stöcker, M.; Gwinup, D.; Szostak, R.; Vinje, K.; Bull. Soc. Chim. Fr. 1992, 129, 98.

51. Sheldon, R. A.; Wallau, M.; Arends, I.W.E.C; Schuchardt, U.; Acc. Chem Res. 1998, 31, 485.

52. Lempers E. B.; Sheldon, R. A.; Stud. Surf. Sci. Catal. 1997, 105, 1061.

53. Haanepen, J. M.; Mehring, A. M. E.; van Hoof, J. H. C.; Appl. Catal. 1996, 152, 203.

54. Peeters, M. P. J.; Busio, M.; Leijten, P.; Appl. Catal. 1994, 118, 51

55. Vanoppen, D. L.; De Vos, D. E.; Genet, M. J.; Rouxhet, P. G.; Jacobs, P. A. Angew. Chem, Int. Ed. Engl. 1995, 34, 560 .

56. Sanseverino, A. M.; Quim. Nova 2000, 23, 102.

57. Thomas, J.M; Scientific American 1992, 112.

58. Barton, D; Li, T. MacKinnon, J.; Chem. Commun. 1997, 6, 557.

59. Parton, R.; Peere, G.; Neys, P.; Jacobs, P; Claesens, R; Baron, G.; J. Mol. Catal. A: Chemical 1996, 113, 445.

60. Luna, F. J; Ukawa, S.E.; Wallau, M; Schuchardt, U.; J. Mol. Catal. A: Chemical, 1997, 117, 405. 